Sources of about 5,000 curies mounted in a $5-\mathrm{cm}$. cube could be used in place of an X-ray teletherapy unit and, unlike the latter, could not fail at a critical moment. Such cæsium-137 sources would also be ideal for use by industry in research and development on radiation chemistry. Dr. J. W. Arrol (Harwell) described the handling and uses of some other fission products. Iodine-131 is used extensively in medicine, and the plant for its large-scale production from fission products was described. The rare gas, krypton-85, is particularly valuable because of its chemical inertness and its radioactive long life. The fact that it is almost a pure beta-emitter makes it possible to handle very high activity sources with little shielding. Its use as a static eliminator, in ventilation control, and for sterilization of blood plasma was suggested.

As a result of this symposium it became clear that the following steps should be taken if the full and efficient use of the radiation from fission products is to be ensured in Great Britain. The assistance of university research departments should be enlisted in an effort to build up gradually a systematic chemistry of radiation effects, particularly in mixtures of organic substances. Industrial research laboratories should be encouraged to use the sources now becoming available to carry out short-term studies of radiation effeats which may be of special interest to them. The technical problems of preventing unpleasant taste and odour and of ensuring safety of the product clearly require further attention in the field of food preservation and pharmaceutical sterilization. Realistic estimates of the cost of making available large fission-product sources from existing and from future plant should be prepared. Plans already made for the production of sources of high specific activity from fission-product wastes should be implemented, since this will not only provide sources for medical and industrial use but will also furnish the basic information needed for technical and economic estimates of future large-scale production of sources.

As information becomes available from this work, the overall advantages of using fission-product radiation must be assessed on a national basis and, by close collaboration between the atomic energy project and potential users, a scheme should be worked out for apportioning the additional cost of providing the facilities.

The papers presented at this symposium, together with a full account of the discussion, are being prepared as a Harwell report, and will be on sale at Her Majesty's Stationery Office. The present account is published by permission of the Director of the Atomic Energy Research Establishment.

$$
\text { G. N. WALTON }
$$

J. WRIGHT

\section{SOLUTIONS OF ELECTROLYTES IN ORGANIC SOLVENTS}

A SYMPOSIUM on "Solutions of Electrolytes in Organic Solvents" was held at Buckland House, Buckland, Berks, on April 15 by invitation of the Physical Chemistry Group of the Atomic Energy Research Establishment, Harwell. About fifty people attended, including visitors from various universities and institutions in the United Kingdom and overseas. The meeting was under the chairmanship of Dr. E. Glueckauf (Harwell), who, in his opening remarks, said that the nine papers to be discussed were grouped into three sections : solvent extraction and the nature of addition complexes; acid-base phenomena in nonaqueous solutions; and the constitution of solutions contrining iodine.

The first paper, by T. V. Healy and Dr. G. M. Waind (Harwell), was on "The Extraction of Metal Nitrates into Phosphate Esters". Mr. Healy discussed the differences in the extraction of cobalt, sodium, and uranyl nitrates from aqueous solutions by tributyl phosphate, and also partition data for uranyl nitrate between water and the solvents dibutylphenyl phosphate, diphenylbutyl phosphate and triphenyl phosphate. He showed that the thermodynamic equilibrium constants and free energies of transfer of uranyl nitrate between the various solvents are in the order expected from the electron-donor properties of the solvents. Deviations from ideality above $0 \cdot 1 M$ were used for estimating approximate solvation numbers for the complexes (for example, $n=2$ for $\left.\mathrm{UO}_{2}\left(\mathrm{NO}_{3}\right)_{2} \cdot n(\mathrm{BuO})_{3} \mathrm{PO}\right)$. More accurate values were obtained from partition data (with organic concentrations $<0.1 M$ ) in the presence of inert diluents, in conjunction with solvent activities obtained from vapour-pressure measurements.

Dr. H. M. Feder (Argonne National Laboratory, Chicago), in a paper entitled "The Stability of Molecular Addition Compounds : a Solubility Technique", dealt with the formation of compounds between mercuric chloride and various alcohols and carbonyl compounds in carbon tetrachloride. Although equilibrium was reached more slowly in organic media than in aqueous solutions, the results were reproducible, and enthalpy, free energy and entropy changes for the reactions were evaluated with good precision. After discussing the applicability and limitations of the solubility technique, Dr. Feder presented results on uranyl nitrate dihydrate with a wide variety of organic bases (donors). Formation constants thus obtained were compared in terms of the general Lewis acid - base theory, as modified by steric requirements.

The discussion on these two papers was opened by Prof. W. F. K. Wynne-Jones (Newcastle upon Tyne), who criticized the use of the term 'base strength' when applied to Lewis donor species. He pointed out that the term can be precisely and usefully defined in the conventional way in aqueous systems, and showed that an attempt to generalize this to obtain a sequence of base strengths valid for all systems merely results in a confused state where a unique order is not even defined within the one solvent. This was supported by Prof. J. A. A. Ketelaar (Amsterdam). In answer to R. P. Bell (Oxford), Mr. Healy said that the water content and electrical conductivity of sodium nitrate solutions in phosphate esters have not
yet been determined.

In the session before luncheon, two papers were read from the Atomic Energy Research Establishment, Harwell. H. A. C. McKay, who spoke on "The Partition of Nitric Acid between Water and Ethers", considered first the binary water - ether systems. The differential heats of mixing indicate compound formation, and the water-vapour pressure curve in the water - pentaether system indicates interaction between the dissolved water molecules in the pentaether. In polyethers, the oxygen atoms appear to act independently of each other when forming complexes with water or uranyl nitrate. Mr. McKay said that conductivity and viscosity measurements show that, in most cases, the nitric acid may be considered as 
un-ionized in the ether phase, so far as partition results are concerned. The amount of water accompanying the nitric acid into the organic phase varies considerably from ether to ether. The paper concluded with a discussion of the plots of nitric acid activity against the mole ratio of nitric acid to ether, which are strictly linear only at the lowest concentrations.

Dr. Glueckauf's paper on "The Ternary System Nitric Acid - Water - n-Butyl Ether" was a thermodynamic analysis based on partition experiments (activities), phase composition data, and molal heat contents obtained by Miss B. L. Ford (Harwell). The four characteristic features of the system are : complex formation, with hydrogen bonding, of butyl other and nitric acid in $1: 1$ ratio $(-\Delta H=$ $7 \mathrm{kcal} . / \mathrm{mole}$ ); association of this complex with water; partial formation of a bimolecular species

$$
\left(\mathrm{Bu}_{2} \mathrm{O} . \mathrm{HNO}_{3}\right)_{2}, x \mathrm{H}_{2} \mathrm{O}(x<1) \text {, }
$$

as indicated by the trend of activities; absorption of nitric acid as a species in which the $1: 1$ ratio is exceeded, in those solutions where the mole ratio of nitric acid to ether approaches unity. This species has a much higher heat content $(\Delta \mathrm{H} \simeq 3 \mathrm{kcal} . / \mathrm{mole}$ nitric acid) than the normal $1: 1$ complex, and the trends of activities and heat contents are consistent with bimolecular association. Dr. Glueckauf said that these four types of interaction are typical of the ternary systems of all ethers in equilibrium with aqueous nitric acid solutions.

In the discussion, Prof. Wynne-Jones directed attention to the difficulty of obtaining precise formula for the addition complexes from purely thermodynamic arguments, and Dr. Feder suggested that, with so many simultaneous equilibria, progress in the detailed understanding of such a ternary system by this method might be rather slow. Mr. Bell and Prof. Ketelaar alluded to the possibility of identifying the complexes postulated by ultra-violet absorption spectroscopy. Dr. Glueckauf replied that two-phase equilibration, using solutions of known activity, permits observations over a greater range than can be attained by almost any other method, and he recommended its wider application, preferably in combination with other techniques.

The first speaker in the afternoon was Prof. WynneJones, who contributed a paper on "The Interaction of Acids and Bases in Non-Aqueous Solvents". After a brief historical survey which stressed the influence of hydrogen bonding in reducing the degree of ionizaticn in non-equeous systems, he pointed out that such bonding may result in both a displacement of the absorption bands and also a marked entropy change. This was illustrated by results on the interaction between a number of amines and nitrophenols in benzene solutions. By measuring the absorption for different acid/base ratios at a series of temperatures, full thermodynamic data were obtained for the equilibria. The strikingly large entropy effects ( 30 cal. deg. ${ }^{-1}$ mole $^{-1}$ ) were explained by assuming that the benzene molecules are powerfully oriented by the strongly polar compounds. Prof. Wynne-Jones related these results to the mechanism of the Menschutkin reaction and concluded by observing that, in such solvents, the concepts of acid and base tend to lose their sharpness of definition.

Dr. D. D. Eley (Bristol) then presented a paper on "Solutions of Aluminium Halides" which discussed recent results obtained in collaboration with Dr. P. J. King (Bristol). Whereas aluminium bromide gives an ideal solution of $\mathrm{Al}_{2} \mathrm{Br}_{6}$ molecules in benzene, addition of hydrogen bromide results in the formation of two liquid phases. The upper phase has a low electrical conductivity; but the lower phase, of composition $\mathrm{Al}_{8} \mathrm{Br}_{6} \cdot \mathrm{HBr} .6 \mathrm{C}_{6} \mathrm{H}_{8}$, is highly ionized. Before addition of hydrogen bromide, the solution has an absorption band at $2785 \mathrm{~A}$. due to $\mathrm{Al}_{2} \mathrm{Br}_{6} \cdot n \mathrm{C}_{6} \mathrm{H}_{8}$; this may be attributed to a charge-transfer spectrum. The introduction of hydrogen bromide suppresses this band, and a new absorption appears at $3300 \mathrm{~A}$. which eventually spreads to $5500 \mathrm{~A}$. at high concentrations, Dr. Fley said that an increase in the pressure of hydrogen bromide, while effecting relatively little variation in the composition of the individual phases, caused the lower to grow at the expense of the upper.

There was a lively discussion of both these papers. Prof. R. S. Mulliken (Chicago), Dr. F. Fairbrother (Manchester) and Dr. N. N. Greenwood (Harwell) spoke of the possible structure of the molecular addition compounds and of the relation of Dr. Eley's results to those in systems containing aluminium chloride and boron trifluoride. Dr. A. R. Mathieson (Nottingham) reported some observations on the effect of aluminium chloride on the spectrum of benzene in $n$-hexane solution : whereas the benzene bands between 2400 and 2650 A. are unaffected, aluminium chloride enhances the absorption below 2400 A. This absorption does not obey Beer's law and suggests formation of a complex. Dr. Mathieson also pointed out that the single peak at $2820 \mathrm{~A}$., obtained for a solution of aluminium chloride in pure benzene, is similar to that observed for a solution of aluminium bromide in the same solvent.

The last group of papers dealt with solutions containing iodine. Dr. L. I. Katzin (Argonne National Laboratory, Chicago) spoke on "Solvation Effects in the Tri-iodide Equilibrium". He first considered the general effects of dielectric constant, donor strength, and stoichiometry on solvation, and then discussed some results obtained with aqueous $t$-butyl alcohol solutions of $t$-butylammonium iodide or sodium iodide, in the presence of iodine. The tri-iodide dissociation constants were obtained by a spectrophotometric dilution technique, using the absorption peak at $3550 \mathrm{~A}$. This gave, independently, both the dissociation constant and the extinction coefficient. Dr. Katzin showed that the shape of the curves of optical density against water content for sodium tri-iodide can be ascribed to a cation hydration effect which is largely complete at low water concentrations. The significance of these results for theories on the constitution of iodine solutions was outlined.

Prof. Ketelaar followed with a paper on "The Colour and Constitution of Iodine Solutions". He pointed out that specific solvation of iodine in solvents such as the chlorinated olefins, though well established, is yet so weak as to leave unaffected the visible absorption spectrum. In the ultra-violet, however, absorption due to the complexes formed is observed. Prof. Ketelaar said that, in a group of related compounds, there is a linear correlation between both the free energy and heat of formation, on one hand, and the frequency of absorption and ionization potential of the donor, on the other. Using benzene as an example, he calculated the difference in bonding energy between the two configurations of the resonance-complex, and showed that this decreases with increasing methyl substitution.

Dr. Greenwood presented the final paper of the symposium, dealing with "The Electrical Conductivity and Colour of Iodine Solutions". Experiments were 
described which correlated the colour, conductivity and chemical reactivity of solutions containing iodine, bromine, iodine monochloride or iodine monobromide. He showed that, whereas all violet solutions of iodine are non-conducting, brown solutions conduct ionically by virtue of the equilibrium :

$$
\text { solvent }+2 \mathrm{I}_{2} \rightleftharpoons \text { solvent } \mathrm{I}^{+}+\mathrm{I}_{3}-\text {. }
$$

When a donor solvent is added to a violet solution, it turns brown with simultaneous onset of conductivity. Again, the effect of heat, in tending to alter brown solutions reversibly to violet, is paralleled by a decrease in conductivity which increases again on cooling. Dr. Greenwood pointed out that ionic reactions typical of either the iodine cation or the tri-iodide anion occur rapidly in brown solutions but not in violet solutions, and that there are important similarities between the ultra-violet spectra of brown solutions and the spectrum of the tri-iodide ion.

Prof. Mulliken opened the discussion of these papers by considering in detail the nature of the jodine complexes and their relation to charge-transfer spectra. The structure of the tri-iodide ion was also discussed. Mr. Bell described experiments designed to measure the concentration of positive iodine in strongly acid solutions, and contributions were also made by Dr. Fairbrother and Prof. Wynne-Jones on the significance of dipole measurements in solutions containing iodine and the use of spectrophotometric techniques to obtain equilibrium constants in solution.

The symposium concluded with a short summary of the day's proceedings by Prof. Wynne-Jones. Informal discussions were continued after dinner and provided a fitting sequel to a pleasant day at Buckland House.

N. N. GREENWOOD

\section{SOUTH-WESTERN NATURALISTS' UNION}

\section{CONFERENCE AT ILFRACOMBE}

$\mathrm{T}$ HE South-Western Naturalists' Union held its twenty-sixth annual Whitsuntide Conference at Ilfracombe during May 22-25, at the invitation of the Ilfracombe Field Club. The meeting opened with a reception on May 22, when the chairman of the Ilfracombe Urban District Council, Mr. H. P. Smith, welcomed the members; afterwards, Mr. E. Gill showed a series of films illustrating marine and terrestrial life.

On May 23, the general annual meeting of the Union was held, the chair being taken by the president of the Union, Mr. Mervyn G. Palmer. In his report the honorary secretary, Dr. Stanley Smith, stated at the present time the Union embraces twenty natural history societies, one institution and one private member; since the last general meeting, held at Plymouth on June 2, 1952, the Salisbury and District Naturalists' Field Club has become affiliated. He announced that three of the affiliated societies, together with a fourth body, have acquired the tenancy of Steep Holm in order to preserve its natural amenities and to make these available to naturalists. Particulars concerning the conditions under which permission to visit the island are granted can be obtained from Mr. J. H. Savory, 61 Lower Redland Road, Bristol 6. Dr. Smith also directed the attention of the Union to the lamentable destruction of the Long Barrow near Marlborough, Wiltshire. A resolution was passed expressing the Union's con- cern at the loss of these ancient monuments. A letter from the secretary of the Bristol Naturalists' Society, Mr. C. S. Carlile, inviting the Union to hold its next conference at Bristol was read, and this invitation was unanimously accepted.

The election of officers for 1954 concluded the proceedings. Mr. E. R. Harris (Plymouth) was elected president; and the honorary secretary, Dr. Stanley Smith, the honorary treasurer, Mr. H. W. Turner, and the honorary auditor, Dr. F. S. Wallis, were asked to remain in office. Mr. C. S. Carlile and Mr. R. W. Hall were added to the Council.

In the afternoon, members visited Arlington Court, which for many generations had been the home of the Chichester family and is now the property of the National Trust. In the evening, a lecture on "High Lights and Shadows of Bird Photography" was given by Mr. E. H. Ware.

A comprehensive tour of north-west Devonshire occupied the whole of May 24. On the outward journey St. Nectan's Church, Stoke, was visited and the contorted strata at Hartland Quay were examined. At Hartland Abbey the party was met by Major Stuckley, the owner, and was conducted by him over the house, which is of considerable architectural interest and contains many treasures. On the property is one of the few remaining breeding grounds of the large blue butterfly (Maculinea arion (Linn.)). Major Stuckley explained that the area has been fenced around, in an endeavour to preserve the insect, the remarkable life-history of which he briefly outlined. Members were shown over Clovelly Dykes (earth-works attributed by Lady Fox to Iron Age $B$ ) by Mr. J. C. and Mrs. Hilton. Mr. Hilton also showed flint arrow-heads and other stone implements found in the neighbourhood. He explained that the flint-working site was within a quarter of a mile of the Dykes.

There was a short excursion on the morning of May 25 to Chapel Wood Bird Sanctuary, Spreacombe, owned by the Royal Society for the Protection of Birds and under the administration of the Ilfracombe Field Club.

\section{NATIONALIZED INDUSTRIES IN GREAT BRITAIN \\ RELATIONS WITH THE PUBLIC}

$T$ HE Acton Society Trust has published a number of studies surveying certain aspects of the nationalized industries that appear to be specially important, and the last of these studies, No. 12, deals with the relations which are being developed between the nationalized industries*. It is a subject of crucial importance, and, although some parts of it have been discussed in earlier studies, this brief account of the arrangements so far made to foster relations with the public bears closely on the three main topics to which the previous studies have been devoted. A satisfactory solution of this problem would go far to resolve that of the accountability of the industries to Parliament or of their internal industrial relations, and might even contribute substantially to remove some of the difficulties noted in the distribution of authority and the supply of those qualified to wield authority.

* Acton Society 'Trust. Nationalized Industry Series 12 : Relations with the Public. Pp. 39 . (From the Trust, 39 Welbeck Street, London, W.1. 1953.) 28 . 